\title{
Epidemiology of sepsis in Catalonia: analysis of incidence and outcomes in a European setting
}

\author{
Juan Carlos Yébenes ${ }^{1,2,3,16^{*}}$, Juan Carlos Ruiz-Rodriguez ${ }^{4,5}$, Ricard Ferrer ${ }^{4,5,6}$, Montserrat Clèries ${ }^{7}$, Anna Bosch7, \\ Carol Lorencio ${ }^{8}$, Alejandro Rodriguez ${ }^{2,9,10}$, Xavier Nuvials ${ }^{11,12}$, Ignacio Martin-Loeches ${ }^{13}$, Antoni Artigas $6,14,15$ \\ and SOCMIC (Catalonian Critical Care Society) Sepsis Working Group
}

\begin{abstract}
Background: Up-to-date identification of local trends in sepsis incidence and outcomes is of considerable public health importance. The aim of our study was to estimate annual incidence rates and in-hospital mortality trends for hospitalized patients with sepsis in a European setting, while avoiding selection bias in relation to different complexity hospitals.

Methods: A large retrospective analysis of a 5-year period (2008-2012) was conducted of hospital discharge records obtained from the Catalan Health System (CatSalut) Minimum Basic Data Set for Acute-Care Hospitals (a mandatory population-based register of admissions to all public and private acute-care hospitals in Catalonia). Patients hospitalized with sepsis were detected on the basis of ICD-9-CM codes used to identify acute organ dysfunction and infectious processes.

Results: Of 4,761,726 discharges from all acute-care hospitals in Catalonia, 82,300 cases (1.72\%) had sepsis diagnoses. Annual incidence was 212.7 per 100,000 inhabitants/year, rising from 167.2 in 2008 to 261.8 in 2012. Length of hospital stay fell from 18.4 to 15.3 days $(p<.00001)$, representing a relative reduction of $17 \%$. Hospital mortality fell from 23.7 to $19.7 \%(p<.0001)$, representing a relative reduction of $16.9 \%$. These differences were confirmed in the multivariate analysis (adjusted for age group, sex, comorbidities, ICU admission, emergency admission, organ dysfunction, number of organ failures, sepsis source and bacteraemia).
\end{abstract}

Conclusions: Sepsis incidence has risen in recent years, whereas mortality has fallen. Our findings confirm reports for other parts of the world, in the context of scarce administrative data on sepsis in Europe.

Keywords: Sepsis, Septic shock, Mortality, Epidemiology

\section{Background}

Sepsis has been recently redefined as an infection that leads to organ dysfunction [1]. Although a hospitalized patient with sepsis is more likely to die than a patient with heart attack or stroke [2], sepsis is still not evaluated with the same urgency as other critical conditions. Sepsis mortality can be reduced considerably by adopting early

\footnotetext{
*Correspondence: jyebenes@csdm.cat

${ }^{16}$ Servei de Medicina Intensiva, Hospital de Mataró, Carretera de Cirera s/n, 08304 Mataró, Spain

Full list of author information is available at the end of the article
}

recognition protocols and using standardized emergency treatment, but fewer than 1 in 7 patients are actively intervened in this way [3]. Treatment ineffectiveness is often due to late sepsis diagnosis-mainly a failure by caregivers or healthcare professionals to suspect sepsis. The clinical symptoms and laboratory signs currently used for diagnostic purposes are not specific for sepsis, and there is a lack of reliable systems for timely detection of septic patients.

Proper detection of sepsis and its progression are essential to patient management. Epidemiology case studies using administrative hospital data have reported both 
growing incidence and declining mortality rates associated with severe sepsis in several different countries but mainly in the USA, Australia and New Zealand [4-11]. However, administrative data may be affected by changes in coding practices that distort incidence and mortality estimates. Recently, Stevenson et al. [12] compared incidence and mortality trends in trial data with those observed in administrative data, observing that, since 1991, risk-standardized 28-day severe sepsis mortality has tended to decline in parallel for both methods; this which would indicate that trends in severe sepsis mortality as calculated from administrative data and International Classification of Diseases, 9th revision, Clinical Modification (ICD-9-CM) algorithms are likely to be accurate.

Catalonia, an autonomous region in Spain, has actively begun to advocate more vigorous efforts to decrease the sepsis burden through the development of an Inter-hospital Sepsis Emergency Code, operational between the Catalan Health Service (CatSalut) and seven local medical societies [13]. Since the identification of trends in sepsis outcomes is of considerable public health importance, the aim of our study was to estimate population and annual in-hospital incidence rates and in-hospital mortality trends for patients with sepsis between 2008 and 2012 in Catalonia, before implementation of the Interhospital Sepsis Emergency Code designed to coordinate and optimize care of patients with sepsis.

\section{Methods}

\section{Data sources}

A retrospective analysis was conducted of hospital discharge records from the Minimum Basic Data Set for the Catalan Health System (CatSalut) Acute-Care Hospitals (a mandatory population-based register of admissions to all public and private acute-care hospitals in Catalonia) enables evaluation and optimization of resource use, provides support to and improves healthcare planning and facilitates procurement management and payments. To ensure data quality, the CMBD-HA input data are systematically validated internally and periodically validated externally. The data set contains demographic and clinical data for patient care episodes, including age, sex, length of stay (days), one primary diagnosis, up to nine secondary diagnoses, one primary procedure, up to seven secondary procedures and status on discharge (alive or dead). Official data from the register of insured persons maintained by CatSalut were used to estimate crude and specific hospitalization rates (universal coverage for $7,601,813$ inhabitants in 2012).

\section{Patients}

Sepsis, formerly severe sepsis [1] was defined by the presence of infection and at least one organ dysfunction.
Patients hospitalized with sepsis were detected, according ICD-9-CM codes used to identify acute organ dysfunction and infectious processes following the Angus methodology [5], over a 5-year period (2008-2012). To avoid overlaps, we excluded patients who were transferred from one acute-care hospital to another during the same severe sepsis episode.

\section{Coding}

Diagnoses and procedures were coded using the ICD9-CM, whose codes to identify patients with sepsis were updated in 2000 to the following: 995.91 (sepsis), 995.92 (severe sepsis) and 785.52 (septic shock) (Supplementary Appendix: Additional file 1). Although information was not available regarding the unit or department where patients were treated (intensive care unit (ICU), internal medicine unit, etc.), we indirectly deduced ICU admission from procedures typically used in intensive care management (Supplementary Appendix: Additional file 1). The Charlson comorbidity index with its 17 comorbid disease categories [13] was used to assess the presence of underlying comorbidities. The ICD-9-CM codes used to identify acute organ dysfunction and infectious processes are listed in Supplementary Appendix: Additional file 1.

\section{Statistical analysis}

The hospitalization rate was defined as the yearly number of admissions per 100,000 population (excluded were 1590 admissions from non-residents in Catalonia). Crude overall and specific hospitalization rates by age and sex were calculated. Continuous variables and discrete variables were compared using analysis of variance and the Chisquare test, respectively. Multivariate logistic regression, adjusted for other significant variables, was used to analyse hospital mortality risk by year of admission for the study population and for the ICU and non-ICU patient groups; variables were entered one by one and retained when their significance was $<.10$ and were clinically plausible. For the regression analysis, each of the clinical attributes included (comorbidities, acute organ failure and infection) were treated as binary (dummy) variables indicating the presence or absence of these conditions; a single patient could therefore account for more than one attribute. The area under the receiver operating characteristic curve (AUROC) was used to evaluate how well the multivariate logistic regression model discriminated between patients with severe sepsis who were discharged alive versus those who died inhospital [14]. Data analysis was performed using SPSS 18.0 software (SPSS Inc, Chicago, IL, USA).

\section{Results}

Incidence and main features of severe sepsis

Of 4,761,726 discharges from all acute-care hospitals during the study period, 82,300 (1.72\%) had 
sepsis. Demographic characteristics and comorbidities for patients with sepsis are shown in Table 1.

Annual incidence in the population was 212.7 per 100,000 inhabitants/year, increasing from 167.2 in 2008 to 261.8 per 100,000 inhabitants/year in 2012 (Fig. 1). Sepsis was significantly associated with age (more frequent in older patients) and sex (208.3 cases for men versus 156.0 cases for women per 100,000 inhabitants/year) (Fig. 2).

The most frequent origins of sepsis were urinary and respiratory tract infections, accounting for 37.2 and $32.5 \%$ of cases, respectively, followed by the abdomen (11\%). Almost a quarter (24.7\%) of cases presented bacteraemia. Acute kidney injury was the most frequent organ failure $(58.4 \%)$, followed by respiratory failure (20.5\%) and central nervous system failure (19.7\%). Cardiovascular dysfunction was reported in $4.9 \%$ of cases. Two or more acute organ failures were documented in $14 \%$ of cases (Table 1).

\section{Hospital outcomes}

In-hospital mortality over the study period was $21.6 \%$ (95\% confidence interval (CI); 18.6-24.9). Hospital mortality was higher in older patients with higher Charlson comorbidity score, in patients with bacteraemia $39.3 \%$ in patients with positive versus $15.8 \%$ in patients with negative blood cultures), and was also higher in patients with more organ failures (three or more, 63.4\%). Respiratory and abdominal origins were associated with higher mortality (24 and $28 \%$, respectively). Mean (SD) length of stay was 16.7 (19.5) days, with no clinically relevant differences for patients who died in-hospital versus who were discharged alive (despite a value of $p<.001$ ) (Table 1 and Table 2).

\section{Incidence and in-hospital outcome trends}

Incidence of sepsis increased in the five-year study period from 12,809 cases to 20,228 cases (mean 16,460 cases per year over the period), representing 1.3 and $2.1 \%$ $(p<.0001)$ of hospital admissions, respectively (Fig. 2). Observed in the same period were an increase in mean age, from 69.1 to 72.8 years $(p<.0001)$, and an increase in mean Charlson comorbidities score, from 4.9 to 5.3 $(p<.001)$ (Fig. 3).

Length of hospital stay decreased from 18.4 to 15.3 days $(p<.0001)$, representing a relative reduction of $17 \%$ (Fig. 3). Univariate analysis showed that hospital mortality also decreased-from 23.7 to $19.7 \%$ ( $p<.0001$ )-for a relative reduction of $18.6 \%$ (Fig. 2). These differences were confirmed in the multivariate analysis adjusted for all significant variables (age group, sex, comorbidities, ICU admission, emergency admission, organ dysfunction, number of organ failures, infection source and presence of bacteraemia) (Tables 1, 2). Differences between 2008 and all the ensuing years except 2009 were statistically significant. The logistic regression (reference year 2008) indicated a mortality odds ratio (OR) for patients with sepsis in 2012 of 0.772 (95\% CI 0.727-0.820) (Table 3). The falling trend in the mortality OR was linear throughout the study period for all patients with sepsis, whether or not treated in the ICU. Values for the AUROC were calculated to evaluate how well the multivariate logistic regression model discriminated between patients discharged alive and discharged dead: 0.782 (95\% CI 0.779 $0.786)$ for all patients, $0.746(0.741-0.752)$ for non-ICU patients and $0.749(0.743-0.756)$ for ICU patients.

\section{Discussion}

Most epidemiological data on sepsis refers to the first decade of twenty-first century and almost exclusively refer to the USA. This is a large observational study of patients discharged from all national health system acute-care hospitals conducted in a European setting. We estimated the mean sepsis incidence to be 212.7 cases per 100,000 inhabitants/year and in-hospital mortality to be $21.6 \%$. Incidence and mortality varied over time, with a yearly increase in incidence of $7.3 \%$, a yearly relative reduction of $3.3 \%$ in length of stay and a yearly reduction in in-hospital mortality of $3.4 \%$. After adjustments for relevant clinical and epidemiological variables, the reduction in mortality remained statistically significant.

The estimated incidence of sepsis in our study was lower than reported in the USA and slightly higher than reported in smaller European studies [2, 6, 7]. Previous studies conducted in Spain reported incidences of between 110 and 230 cases per 100,000 inhabitants/year $[15,16]$, versus the 212.7 cases observed in our study. Differences in calculated incidences may be related to structural or functional organization [17] or may be due to discharge diagnosis coding. Nonetheless, we would like to emphasize the importance of using local data to monitor trends in activity and results over time. Moreover, the number of sepsis cases in our study increased yearly, a finding which is consistent with findings reported in other epidemiological studies [10-12].

Estimates of sepsis incidence and trends are also essential to estimate the resources needed to care for these patients. Sepsis incidence is increasing compared to incidence for other leading causes of mortality such as acute myocardial infarction or ischaemic stroke. The CatSalut data on hospital admissions/year for severe sepsis (fiveyear mean, 16,460 cases) are close to the combined numbers for acute coronary syndrome and ischaemic stroke admissions together, at 11,000 and 8000 , respectively [18, 19]. However, incidence rates for acute coronary syndrome and ischaemic stroke, unlike for sepsis, are stable 
[19-21]. In the USA, the percentage of septic patients with a fatal outcome increased from $14 \%$ in 2000 to $16 \%$ in 2010; in contrast, mortality for respiratory failure decreased from 25 to $17 \%$, for heart attack from 10 to $8 \%$, for cancer from 8 to $4 \%$ and for stroke from 6 to $5 \%$ [22].

Prospective versus retrospective analysis observed differences in incidence and source of sepsis. Prospective monitoring is laborious, costly and complex and can also be affected by issues such as inclusion criteria or data sources [23, 24]. Although retrospective analyses from hospital discharges-as in our study-can also be affected by definitions, codes and analytical methods, they serve an important function in analysing local trends and outcomes. Gaieski [24] observed a 3.5-fold difference in estimates of absolute incidence using different database abstraction methods. Nonetheless, trends were similar irrespective of the methodology. Stevenson et al. [12] recently found that severe sepsis mortality was $10 \%$ higher for patients included in the control group of clinical trials compared to administrative data (collected according to Angus' criteria) [5]; nonetheless, mortality trends were similar, irrespective of the data source-and were also similar to the $3 \%$ yearly reduction found in our study. Stevenson et al. consequently concluded that administrative data are useful in monitoring mortality trends in patients with severe sepsis.

Table 1 Profile of patients with severe sepsis in Catalonia 2008-2012

\begin{tabular}{|c|c|c|c|c|}
\hline & Total $N=82,300$ & $\begin{array}{l}\text { Alive on discharge } \\
N=64,511\end{array}$ & $\begin{array}{l}\text { Dead on discharge } \\
N=17,789\end{array}$ & $p$ \\
\hline & Mean (SD) & Mean (SD) & Mean (SD) & \\
\hline Age (years) & $71.2(19.7)$ & $70.6(20.4)$ & 73.3 (16.6) & $<.0001$ \\
\hline Length of hospital stay (days) & $16.7(19.5)$ & $16.8(19.3)$ & $16.3(20.3)$ & $<.001$ \\
\hline \multirow[t]{2}{*}{ Charlson comorbidity index } & $5.1(2.6)$ & $5.0(2.6)$ & $5.6(2.7)$ & $<.0001$ \\
\hline & $\%$ & $\%$ & $\%$ & $p$ \\
\hline \multicolumn{5}{|l|}{ Age (years) } \\
\hline$<15$ & 3.2 & 3.7 & 1.4 & $<.0001$ \\
\hline $15-44$ & 6.1 & 6.6 & 4.2 & \\
\hline $45-64$ & 16.4 & 16.2 & 17.3 & \\
\hline $65-74$ & 17.5 & 17.3 & 18.4 & \\
\hline $75-84$ & 32.9 & 32.8 & 33.6 & \\
\hline$>84$ & 23.8 & 23.5 & 25.0 & \\
\hline \multicolumn{5}{|l|}{ Sex } \\
\hline Males & 56.7 & 56.1 & 59.0 & $<.0001$ \\
\hline \multicolumn{5}{|l|}{ Comorbidities } \\
\hline Chronic kidney disease & 23.8 & 24.5 & 20.9 & $<.0001$ \\
\hline COPD & 22.4 & 22.9 & 20.6 & $<.0001$ \\
\hline Cancer & 14.5 & 12.5 & 21.5 & $<.0001$ \\
\hline Metastasis & 4.8 & 5.8 & 8.3 & $<.0001$ \\
\hline Peripheral vascular disease & 4.4 & 4.2 & 4.9 & $<.0001$ \\
\hline Complicated diabetes & 4.0 & 4.3 & 3.0 & $<.0001$ \\
\hline Liver disease: mild & 9.7 & 8.7 & 13.1 & $<.0001$ \\
\hline Liver disease: moderate-severe & 3.0 & 2.4 & 4.9 & $<.0001$ \\
\hline Myocardial infarction & 3.8 & 3.6 & 4.7 & $<.0001$ \\
\hline Congestive heart failure & 20.1 & 19.1 & 23.8 & $<.0001$ \\
\hline Cerebrovascular disease & 6.7 & 6.5 & 7.6 & $<.0001$ \\
\hline AIDS/HIV infection & 1.0 & 0.9 & 1.3 & $<.0001$ \\
\hline Emergency stay (\%) & 89.4 & 89.8 & 87.8 & $<.0001$ \\
\hline ICU admissions & 28.2 & 22.3 & 49.8 & $<.0001$ \\
\hline \multicolumn{5}{|l|}{ Admission year } \\
\hline 2008 & 15.6 & 15.1 & 17.1 & $<.0001$ \\
\hline 2009 & 17.9 & 17.4 & 19.6 & \\
\hline 2010 & 19.7 & 19.6 & 20.0 & \\
\hline 2011 & 22.3 & 22.6 & 21.0 & \\
\hline
\end{tabular}


Table 1 continued

\begin{tabular}{|c|c|c|c|c|}
\hline & $\%$ & $\%$ & $\%$ & $p$ \\
\hline 2012 & 24.6 & 25.2 & 22.3 & \\
\hline \multicolumn{5}{|l|}{ Sepsis origins } \\
\hline Urinary & 37.2 & 41.1 & 23.0 & $<.0001$ \\
\hline Respiratory & 32.5 & 31.4 & 36.4 & $<.0001$ \\
\hline Abdominal & 11.0 & 10.1 & 14.3 & $<.0001$ \\
\hline Skin and soft tissues & 4.1 & 4.2 & 3.9 & .06 \\
\hline Endocarditis & 1.6 & 1.5 & 2.0 & $<.0001$ \\
\hline Device-related & 1.1 & 1.2 & 0.6 & $<.0001$ \\
\hline CNS & 0.9 & 0.9 & 1.2 & $<.0001$ \\
\hline Others & 37.9 & 41.0 & 26.5 & $<.0001$ \\
\hline Bacteraemia & 24.7 & 19.1 & 44.9 & $<.0001$ \\
\hline \multicolumn{5}{|l|}{ Organ dysfunction } \\
\hline Kidney & 58.4 & 56.9 & 63.7 & $<.0001$ \\
\hline Lung & 20.5 & 15.7 & 37.9 & $<.0001$ \\
\hline CNS & 19.7 & 21.6 & 12.7 & $<.0001$ \\
\hline Haematologic & 11.1 & 11.0 & 11.5 & .054 \\
\hline Cardiovascular & 4.9 & 5.2 & 3.6 & $<.0001$ \\
\hline Liver & 1.3 & 0.7 & 3.3 & $<.0001$ \\
\hline \multicolumn{5}{|c|}{ Number of organ failures } \\
\hline 1 & 86.3 & 89.7 & 72.9 & $<.0001$ \\
\hline 2 & 12.0 & 9.4 & 21.8 & \\
\hline 3 & 1.6 & 0.8 & 4.7 & \\
\hline 4 or more & 0.2 & 0.1 & 0.6 & \\
\hline
\end{tabular}

Data are presented as mean and standard deviation or \%

AIDS acquired immune deficiency syndrome, CNS central nervous system, COPD chronic obstructive pulmonary disease, HIV human immunodeficiency virus, ICU intensive care unit

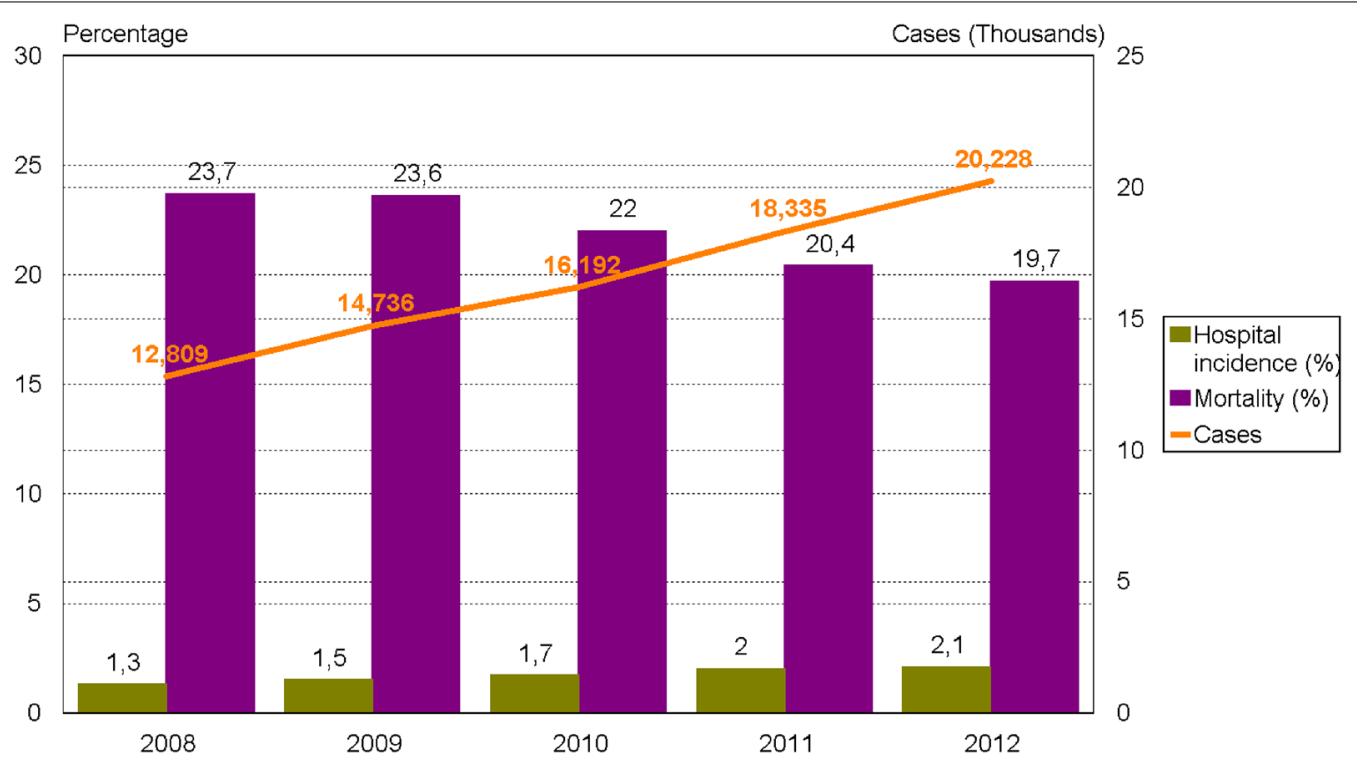

Fig. 1 Number of cases, mortality rates and hospital incidence rates for sepsis in Catalonia (2008-2012). Incidence of sepsis increased from 12,809 cases to 20,228 cases in the 5-year study period (mean 16,460 cases per year), representing 1.3 and $2.1 \%(p<.0001$ ) of hospital admissions and an average yearly increase of $6 \%$. However, hospital mortality decreased from 23.7 to $19.7 \%(p<.0001)$ for a yearly relative reduction of $3.4 \%$ 


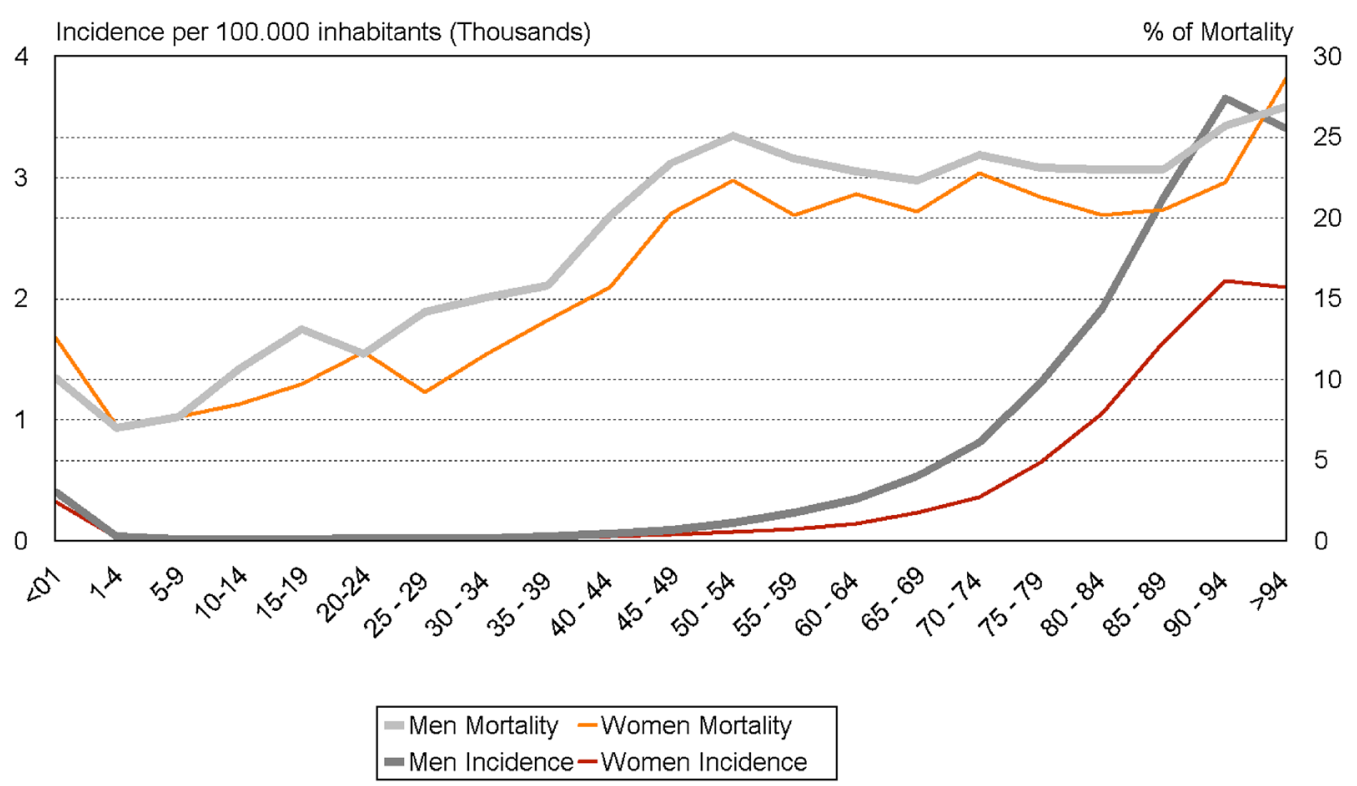

Fig. 2 Age-specific incidence and mortality rates for all cases of severe sepsis by sex in Catalonia (2008-2012). The dark line represents incidence (thicker for men and thinner for women) expressed as a thousand cases per 100,000 inhabitants. Age-adjusted mortality is expressed as the number of deaths with respect to the number of cases grouped according to 5 -year age brackets

Table 2 Overall mortality by patient characteristics, sepsis origins, presence of bacteraemia and organ dysfunction by year of admission in Catalonia (2008-2012)

\begin{tabular}{|c|c|c|c|c|c|c|c|c|}
\hline \multirow[t]{2}{*}{ Condition } & \multirow[t]{2}{*}{$N$} & \multicolumn{6}{|c|}{ Presence of condition (\%) } & \multirow{2}{*}{$\begin{array}{l}\text { In-hospital } \\
\text { mortality (\%) }\end{array}$} \\
\hline & & 2008 & 2009 & 2010 & 2011 & 2012 & $p$ & \\
\hline Mortality & & 23.7 & 23.6 & 22.0 & 20.4 & 19.7 & $<.0001$ & \\
\hline \multicolumn{9}{|l|}{ Source of sepsis } \\
\hline Urinary tract & 30,600 & 33.6 & 35.0 & 37.1 & 39.8 & 38.8 & $<.0001$ & 13.9 \\
\hline Respiratory tract & 26,748 & 34.2 & 34.0 & 31.2 & 30.9 & 32.7 & $<.0001$ & 24.2 \\
\hline Abdomen & 9065 & 10.7 & 11.2 & 11.3 & 11.0 & 10.9 & NS & 28.0 \\
\hline Skin and soft tissues & 3394 & 3.9 & 4.0 & 4.0 & 4.4 & 4.2 & NS & 20.3 \\
\hline Endocarditis & 1326 & 1.8 & 1.8 & 1.9 & 1.4 & 1.4 & $<.0001$ & 27.3 \\
\hline Device-related & 869 & 1.1 & 1.1 & 1.2 & 1.1 & 0.9 & .016 & 11.6 \\
\hline CNS & 775 & 1.2 & 1.1 & 1.1 & 0.7 & 0.7 & $<.0001$ & 27.5 \\
\hline Other & 31,149 & 37.4 & 37.5 & 39.2 & 38.1 & 37.1 & .001 & 15.1 \\
\hline Bacteraemia & 20,285 & 25.5 & 25.5 & 24.5 & 24.8 & 23.5 & $<.0001$ & 39.3 \\
\hline \multicolumn{9}{|l|}{ Organ dysfunction } \\
\hline Kidney & 48,072 & 50.8 & 53.5 & 57.1 & 61.9 & 64.7 & $<.0001$ & 23.6 \\
\hline Respiratory & 16,876 & 26.1 & 24.1 & 20.9 & 17.9 & 16.3 & $<.0001$ & 40.0 \\
\hline CNS & 16,177 & 20.5 & 19.6 & 19.1 & 18.9 & 20.3 & $<.0001$ & 13.9 \\
\hline Haematologic & 9158 & 11.6 & 12.3 & 12.2 & 11.2 & 9.1 & $<.0001$ & 22.4 \\
\hline Cardiovascular & 3988 & 5.3 & 5.4 & 4.7 & 4.6 & 4.4 & $<.0001$ & 16.1 \\
\hline Liver & 1058 & 1.0 & 1.3 & 1.3 & 1.3 & 1.4 & .029 & 55.9 \\
\hline \multicolumn{9}{|c|}{ Number of organ failures } \\
\hline 1 & 70,874 & 86.6 & 85.9 & 86.5 & 86.0 & 85.8 & NS & 18.5 \\
\hline 2 & 9964 & 11.7 & 12.2 & 11.8 & 12.4 & 12.3 & & 39.0 \\
\hline 3 or more & 1462 & 1.7 & 1.9 & 1.9 & 1.7 & 1.8 & & 63.4 \\
\hline
\end{tabular}

Data are presented as number of cases or $\%$

CNS central nervous system, NS non-significant 


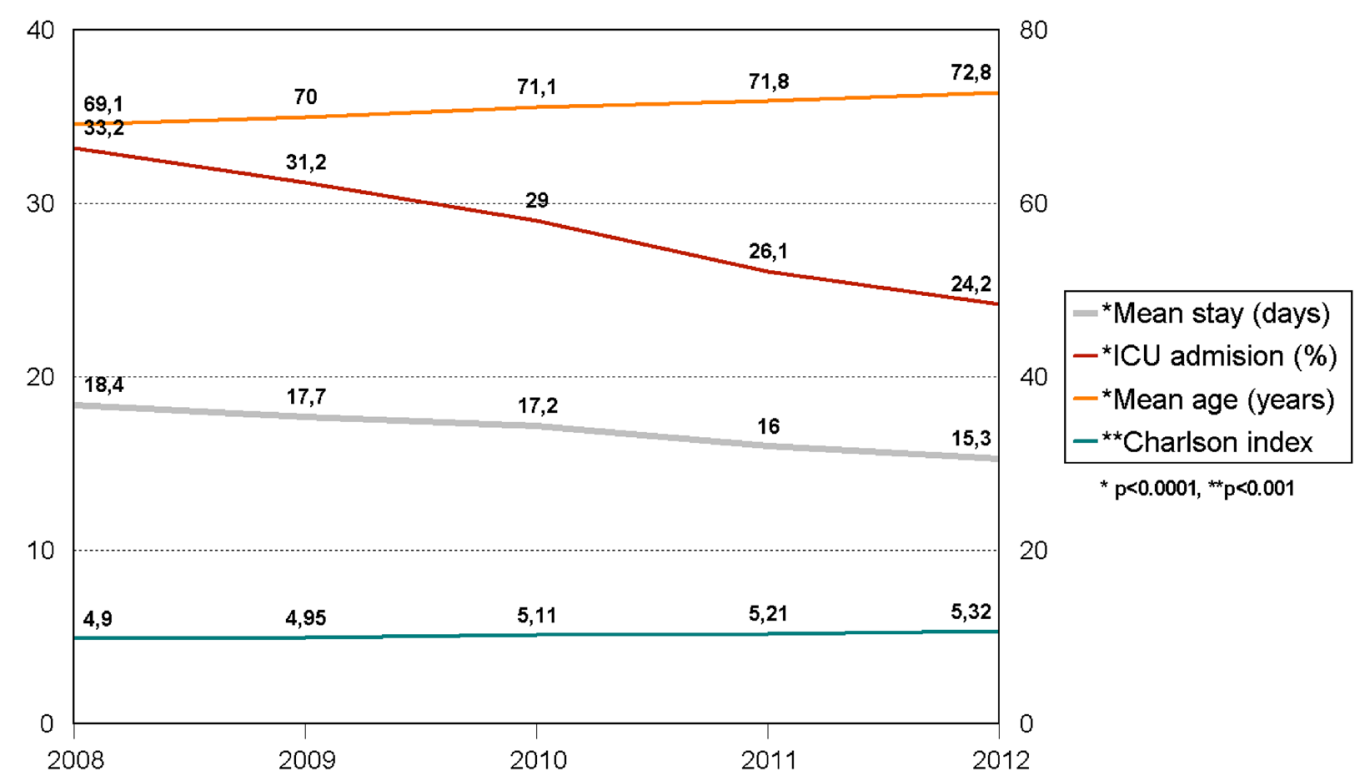

Fig. 3 Trends for main characteristics and hospital stay for patients with sepsis in Catalonia (2008-2012)

Table 3 Univariate and multivariate analyses of in-hospital mortality by year of admission in Catalonia (2008-2012)

\begin{tabular}{|c|c|c|c|c|c|c|}
\hline & \multicolumn{3}{|c|}{ Univariate analysis } & \multicolumn{3}{|c|}{ Multivariate analysis } \\
\hline & $N$ & $\%$ mortality & $p$ & OR & $95 \% \mathrm{Cl}$ for OR & $p$ \\
\hline \multicolumn{7}{|c|}{ All patients $N=82,300$} \\
\hline 2008 & 12,809 & 23.7 & $<.0001$ & 1 & - & - \\
\hline 2009 & 14,736 & 23.6 & & 0.988 & $0.928-1.052$ & NS \\
\hline 2010 & 16,192 & 22.0 & & 0.911 & $0.856-0.969$ & .003 \\
\hline 2011 & 18,335 & 20.4 & & 0.818 & $0.770-0.870$ & $<.0001$ \\
\hline 2012 & 20,228 & 19.7 & & 0.772 & $0.727-0.820$ & $<.0001$ \\
\hline \multicolumn{7}{|c|}{ Non-ICU patients $N=59,064$} \\
\hline 2008 & 8551 & 15.8 & $<.0001$ & 1 & - & - \\
\hline 2009 & 10,137 & 16.3 & & 1.028 & $0.945-1.117$ & NS \\
\hline 2010 & 11,497 & 15.4 & & 0.941 & $0.867-1.022$ & NS \\
\hline 2011 & 13,545 & 14.8 & & 0.859 & $0.793-0.931$ & $<.0001$ \\
\hline 2012 & 15,334 & 13.9 & & 0.769 & $0.711-0.832$ & $<.0001$ \\
\hline \multicolumn{7}{|c|}{ ICU patients $N=23,236$} \\
\hline 2008 & 4258 & 39.5 & .002 & 1 & - & - \\
\hline 2009 & 4599 & 39.6 & & 0.938 & $0.854-1.031$ & NS \\
\hline 2010 & 4695 & 38.2 & & 0.868 & $0.790-0.953$ & .003 \\
\hline 2011 & 4790 & 36.0 & & 0.757 & $0.686-0.832$ & $<.0001$ \\
\hline 2012 & 4894 & 37.6 & & 0.778 & $0.702-0.855$ & $<.0001$ \\
\hline
\end{tabular}

Data are presented as number of death or \%. The multivariate analysis is adjusted by sex, age group, comorbidities, ICU admission, emergency admission, organ dysfunction, number of organ failures, septic origins and bacteraemia

$\mathrm{Cl}$ confidence interval, ICU intensive care unit, OR odds ratio, NS non-significant

Length of stay and mortality both decrease yearly during the study period-to a statistically significant degree according to the multivariate analysis adjusted for demographic data, comorbidities, infection source and number of organ failures. The external validity of our findings is supported by the fact that mortality in 2008 was the same as that reports by the PROWESS-SHOCK study placebo group [25]. Other recent large randomized clinical trials 
(RCTs) have reported mortality rates of $18-30 \%[26,27]$, further confirming the likely validity of 2008 as our baseline year. Kaukonen et al. [11], who recently reported similar results for Australia and New Zealand, observed an annual absolute decrease of $1.3 \%$ in risk, from $24 \%$ in 2008 to $19 \%$ in 2012 . In our study, multivariate analysis revealed a robust association between mortality and year of detection, as adjusted for confounding factors including sex, age group, comorbidities, ICU admission, emergency admission, organ dysfunction, number of organ failures, septic focus and the presence of bacteraemia. Although our study was not designed to address this issue, a potential improvement in the management of sepsis could be suggested, explained in part as a consequence of training and increased clinical awareness [3, 28-30].

Our results suggest also that sepsis outcomes should be interpreted according to the year of data collection and the presence of comorbidities. Moreover, underpowered RCTs would be avoided if these effects were taken into account in estimating statistical power and sample size. Yearly reduction in crude mortality rates should be expected, bearing in mind that overestimated mortality rates may lead to underpowered studies which might, in turn, lead to potentially useful treatments being downgraded due to lack of evidence. Furthermore, excluding elderly patients and patients with comorbidities from RCTs represents a form of selection bias; Kaukonen et al. [11], for instance, reported a $4.6 \%$ mortality rate for comorbidity-free patients and young patients (versus our rate of $21.6 \%$ ). Another issue is that sepsis outcomes are too often viewed as binary: The patient dies (failure) or survives (success). Studies also tend to focus on in-hospital mortality and length of stay as an outcome measure for ICU patients, overlooking the fact that many patients admitted for sepsis die after discharge. There is an unmet need to improve knowledge regarding long-term effects in patients with sepsis [1-8], so other outcome indicators such as long-term morbidity and quality of life are likely to be included in future trials.

Just under a quarter (24.7\%) of our patients presented with bacteraemia, associated with higher mortality. Patients with bacteraemia could represent a suitable population to monitor prospectively in clinical practice, as bacteraemia, unlike sepsis, is easily identified retrospectively, is easily distinguished from other non-infectious diseases that cause organ dysfunction and is also easily stratified using the sepsis-related organ failure assessment (SOFA) instrument [31].

The main strengths of our study are the large cohort of patients included in a European setting, the fact of including $100 \%$ of admissions to both public and private hospitals of Catalonia Health System, the long period of data collection and the use of a previously validated strategy. Our study has several limitations. The fact that cases of sepsis were identified indirectly using ICD-9-CM codes implies less accuracy in identifying cases and a poor clinical analysis compared to prospective methods. Urinary infections appear as the main focus of sepsis in our study. The relevance of each focus can be affected by population characteristics or methodology. It also can affect incidence or severity results. Case recruitment may also have been affected by coding, as reflected in our results for cardiovascular dysfunction. Hypotension was poorly documented on discharge. Incidence, as reported in our study, probably does not reflect clinical incidence. Cardiovascular dysfunction incidence rates of $7.2-42 \%$ have been reported for epidemiological or retrospective studies, in contrast to rates of up $90 \%$ for prospective studies $[4,5,9,13,15$, $32,33]$. Our study cannot account for reasons for reduced mortality and shorter stays. Inclusion of a specific severity scores, such as SOFA, in the multivariate analysis would allow insights into whether mortality reduction is related to the inclusion of less severe patients. Unfortunately, our study design does not admit this conclusion. Given that the CMBD-HA does not specifically collect data about ICU admission, the category 'ICU stay' was deduced from procedures typically used in ICUs. We think that since this definition is highly specific but not sensitive, we cannot rule out the possibility that some septic patients with less severity were excluded from ICU admission.

\section{Conclusions}

Sepsis incidence has risen continuously in recent years in Catalonia. While mortality and length of stay have fallen, despite increases in age and in comorbidities, our findings corroborate results reported for other parts of the world, in the context of scarce administrative data on sepsis in Europe.

\section{Additional file}

Additional file 1. ICD-9-MC codes used to identify infectious process, site of infection, acute organ dysfunction and procedures used in intensive care unit.

\section{Abbreviations}

AIDS: acquired immune deficiency syndrome; Cl: confidence interval; CMBDHA: Minimum Basic Data Set-Acute-Care Hospitals; COPD: chronic obstructive pulmonary disease; ICD-9-CM: International Classification of Diseases, 9th revision, Clinical Modification; ICU: intensive care unit; NS: non-significant; OR: odds ratio; RCT: randomized clinical trials; SD: standard deviation; SOFA: sepsisrelated organ failure assessment.

\section{Authors' contributions}

$J C Y, J C R, R F, M C, A B$ and AA conceived and designed the work. Data acquisition and statistical analysis were performed by $M C$ and $A B$; interpretation of the data for the work was carried out by JCY, JCR, RF, MC, $A B$ and $A A$; all 
authors were involved in draft redaction and/or revision for important intellectual content; all authors read and approved the final manuscript.

\section{Author details}

${ }^{1}$ Critical Care Department, Hospital de Mataró, Mataró, Spain. ${ }^{2}$ Grup de Recerca en Sepsis, Imflamació i Seguretat (AGAUR 2014-SGR926), Barcelona, Spain. ${ }^{3}$ Escola Superior de Ciencies de la Salut, Universitat Pompeu Fabra, Mataró, Spain. ${ }^{4}$ Critical Care Department, Vall d'Hebron University Hospital, Barcelona, Spain. ${ }^{5}$ Shock, Organ Dysfunction and Resuscitation (SODIR) Research Group, Vall d'Hebron Research Institut, Universitat Autònoma de Barcelona, Barcelona, Spain. ${ }^{6}$ CIBER Enfermedades Respiratorias, Madrid, Spain. ${ }^{7}$ Divisió d'Anàlisi de la Demanda i I'Activitat, Servei Català de la Salut (CatSalut), Barcelona, Spain. ${ }^{8}$ Critical Care Department, Hospital Universitari Dr. Josep Trueta, Girona, Spain. ${ }^{9}$ Critical Care Department, Hospital Universitari Joan XXIII, Tarragona, Spain. ${ }^{10}$ IISPV/URV, Tarragona, Spain. ${ }^{11}$ Critical Care Department, Hospital Universitari Arnau de Vilanova, Lleida, Spain. ${ }^{12}$ Institut de Recerca Biomèdica (IRB), Lleida, Spain. ${ }^{13}$ Multidisciplinary Intensive Care Research Organization (MICRO), St James's University Hospital, Trinity Centre for Health Sciences, Dublin, Ireland. ${ }^{14}$ Critical Care Center, Sabadell Hospital, Corporació Sanitaria Universitaria Parc Tauli, Sabadell, Spain. ${ }^{15}$ Universitat Autonoma de Barcelona, Sabadell, Spain. ${ }^{16}$ Servei de Medicina Intensiva, Hospital de Mataró, Carretera de Cirera s/n, 08304 Mataró, Spain.

\section{Acknowledgements}

Group Authorship: SOCMIC (Catalan Critical Care Society) Sepsis Working Group Members: Abdo Taché, Servei de Medicina Intensiva, Hospital Universitari Dr Josep Trueta de Girona; Antoni Margarit, Servei de Medicina Intensiva, Hospital Nostra Senyora Meritxell d'Andorra; Assumpta Ricart, Servei de Urgències, Hospital Universitari Vall d'Hebron; Adolf Ruiz-Sanmartin, Servei de Medicina Intensiva, Hospital Universitari Vall d'Hebron; Begoña Balsera, Servei de Medicina Intensiva, Hospital Universitari Arnau de Vilanova de Lleida; Berta Cisteró, Servei de Urgències, Hospital Parc Taulí de Sabadell; Candelària de Haro, Servei de Medicina Intensiva, Hospital Parc Taulí de Sabadell; Concepció Rovira, Servei de Medicina Intensiva, Hospital Sant Joan de Reus; Eva Torrents, Hospital Parc Taulí de Sabadell; Francisco Álvarez-Lerma, Servei de Medicina Intensiva, Hospital del Mar de Barcelona; Herbert Baquerizo, Servei de Urgències, Hospital Sant Joan de Déu de Manresa; Joan Balcells, Servei de Pediatria, Hospital Universitari Vall d'Hebrón de Barcelona; José L. Echarte, Servei de Urgències, Hospital del Mar de Barcelona; José Luna, Servei de Medicina Intensiva, Hospital de Tortosa Verge de la Cinta; Josep M. Sirvent, Servei de Medicina Intensiva, Hospital Universitari Dr Josep Trueta de Girona; Juan Méndez, Servei de Medicina Intensiva, Hospital de Mataró; Lluís Zapata, Servei de Medicina Intensiva, Hospital de Sant Pau i Santa Creu de Barcelona; Lluïsa Bordejé, Servei de Medicina Intensiva, Hospital Universitari Germans Trias i Pujol de Badalona; Lourdes Jiménez, Servei de Medicina Intensiva, Hospital Universitari Arnau de Vilanova de Lleida; Maite Martínez-Izquierdo, Servei de Urgències, Hospital del Mar de Barcelona; María L. Martínez, Hospital Parc Taulí de Sabadell; María P. Gracia-Arnillas, Servei de Medicina Intensiva, Hospital del Mar de Barcelona; Mercedes Palomar, Servei de Medicina Intensiva Hospital Universitari Arnau de Vilanova de Lleida; Miguel Sánchez, Servei de Urgències, Hospital Clínic de Barcelona; Pablo Pujol, Servei de Medicina Intensiva, Hospital Universitari Dr Josep Trueta de Girona; Pau Garro, Servei de Medicina Intensiva, Hospital General de Granollers; Pau Torrabadella, Servei de Medicina Intensiva, Hospital Universitari Germans Trias i Pujol de Badalona; Paula Vera, Servei de Medicina Intensiva, Hospital de Sant Pau i Santa Creu de Barcelona; Roger Bisbal, Servei de Medicina Intensiva, Hospital de Mataró; Ruth Hernández, Servei de Urgències, Hospital de Sant Joan Despí Moisès Broggi; Teresa M. Tomasa, Servei de Medicina Intensiva, Hospital Universitari Germans Trias i Pujol de Badalona; Víctor Pérez-Claveria, Servei de Urgències, Hospital de Mataró.

\section{Competing interests}

The authors declare that they have no competing interests.

\section{Availability of data and materials section}

The data set supporting the conclusions of this article could be available upon request from cmbd@catsalut.cat.

\section{Ethics approval and consent to participate}

In agreement with Spanish regulations concerning epidemiologic observational studies that do not modify existing diagnosis or therapeutic strategies, no ethics committee approval was required to conduct the study.

\section{Funding}

The study was partially funded by the Mataró Sepsis Challenge (www.sepsischallenge.cat) through the Fundació Salut del Consorci Sanitari del Maresme.

\section{Prior presentation}

This study was reported in part as a communication at the 43rd Annual Congress of the Society of Critical Care Medicine (SCCM, January, 2014, San Francisco, California, USA), the 27th Annual Congress of the European Society of Intensive Care Medicine (ESICM, September 2014, Barcelona, Spain) and the 36th Annual Congress of the Catalan Society of Critical Care Medicine (SOCMIC, March, 2015, Barcelona, Spain).

Received: 1 July 2016 Accepted: 4 February 2017

Published online: 20 February 2017

\section{References}

1. Singer M, Deutschman C, Seymour C, Shankar-Hari M, Annane D, Bauer $\mathrm{M}$, Bellomo R, et al. The third international consensus definitions for sepsis and septic shock (sepsis-3). JAMA. 2016;315:801-10.

2. Hall MJ, Levant S, DeFrances CJ. Trends in inpatient hospital deaths: National Hospital Discharge Survey, 2000-2010. NCHS data brief, no 118. Hyattsville: National Center for Health Statistics; 2013.

3. Ferrer R, Artigas A, Levy MM, Edusepsis Study Group et al. Improvement in process of care and outcome after a multicenter severe sepsis educational program in Spain. JAMA. 2008;299:2294-303.

4. Martin G, Mannino D, Eaton S, et al. The epidemiology of sepsis in the United States from 1979 through 2000. N Engl J Med. 2003;348:1546-54.

5. Angus DC, Linde-Swirble T, Lidicker J, et al. Epidemiology of severe sepsis in the United States: analysis of incidence, outcome, and associated costs of care. Crit Care Med. 2001;29:1303-10.

6. Padkin A, Goldfrad C, Brady AR, et al. Epidemiology of severe sepsis occurring in the first 24 hrs in intensive care units in England, Wales, and Northern Ireland. Crit Care Med. 2003;31:2332-8.

7. Brun-Buisson C, Meshaka P, Pinton P, EPISEPSIS Study Group et al. EPISEPSIS: a reappraisal of the epidemiology and outcome of severe sepsis in French intensive care units. Intensive Care Med. 2004;30(4):580-8.

8. Finfer S, Bellomo R, Lipman J, et al. Adult-population incidence of severe sepsis in Australian and New Zealand intensive care units. Intensive Care Med. 2004;30(4):589-96.

9. Dombrovskiy VY, Martin AA, Sunderram J, et al. Rapid increase in hospitalization and mortality rates for severe sepsis in the United States: a trend analysis from 1993 to 2003. Crit Care Med. 2007;35(5):1244-50.

10. Lagu T, Rothberg MB, Shieh MS, et al. Hospitalizations, costs, and outcomes of severe sepsis in the United States 2003-2007. Crit Care Med. 2012;40(3):754-61.

11. Kaukonen KM, Bailey M, Suzuki S, et al. Mortality related to severe sepsis and septic shock among critically ill patients in Australia and New Zealand, 2000-2012. JAMA. 2014;311(13):1308-16.

12. Stevenson EK, Rubenstein AR, Radin GT, et al. Two decades of mortality trends among patients with severe sepsis: a comparative meta-analysis. Crit Care Med. 2014;42:625-31.

13. Quan $H$, Sundararajan $V$, Halfon $P$, et al. Coding algorithms for defining comorbidities in ICD-9-CM and ICD-10 administrative data. Med Care. 2005;43:1130-9.

14. Hanley JA, McNeil BJ. The meaning and use of the area under a receiver operating characteristic (ROC) curve. Radiology. 1982;143:29-36.

15. Iñigo J, Sendra JM, Díaz R, Bouza C, Sarría-Santamera A. Epidemiology and costs of severe sepsis in Madrid. A hospital discharge study. Med Intensiva. 2006;30:197-203.

16. Andreu Ballester JC, Ballester F, González Sánchez A, et al. Epidemiology of sepsis in the Valencian Community (Spain), 1995-2004. Infect Contro Hosp Epidemiol. 2008:29:630-4.

17. Levy MM, Artigas A, Phillips GS, et al. Outcomes of the Surviving Sepsis Campaign in intensive care units in the USA and Europe: a prospective cohort study. Lancet Infect Dis. 2012;12:919-24.

18. Dégano I, Elosua R, Marrugat J. Epidemiology of acute coronary syndromes in Spain: estimation of the number of cases and trends from 2005 to 2049. Rev Esp Cardiol. 2013;66(6):472-81. 
19. Colls C, Abillera S, Garcia ALtes A, Gallofre M. Beneficis de l'organització de I'atenció sanitària a les persones amb ictus: mortalitat evitada i impacte econòmic. Edita:AQuAS, 1st ed. Barcelona. Observatori del Sistema de Salut de Catalunya; 2013.

20. Sans S, Puigdefabregas A, Paluzie G, Monterde D, et al. Increasing trends of acute myocardial infarction in Spain: the MONICA-Catalonia Study. Eur Heart J. 2005;26:505-15.

21. Gil M, Martı H, Elosua R, et al. Análisis de la tendencia en la letalidad, incidencia y mortalidad por infarto de miocardio en Girona entre 1990 y 1999. Rev Esp Cardiol. 2007;60:349-56.

22. Hall MJ, Williams SN, DeFrances CJ et al. Inpatient care for septicemia or sepsis: a challenge for patients and hospitals. NCHS data brief 2011;62:18. CDC National Hospital Discharge Survey. http://www.cdc.gov/nchs/ nhds.htm. Accessed 17 Oct 2014.

23. Klein Klouwenberg PM, Ong DS, Bonten MJ, et al. Classification of sepsis, severe sepsis and septic shock: the impact of minor variations in data capture and definition of SIRS criteria. Intensive Care Med. 2012;38:811-9.

24. Gaieski DF, Edwards JM, Kallan MJ, et al. Benchmarking the incidence and mortality of severe sepsis in the United States. Crit Care Med. 2013;41:1167-74.

25. Ranieri $M$, Thompson T, Barie $P$, et al. Drotrecogin alfa (activated) in adults with septic shock. N Engl J Med. 2012;366:2055-64.

26. Caironi P, Tognoni G, Masson S, et al. Albumin replacement in patients with severe sepsis or septic shock. N Engl J Med. 2014;370:1412-21.
27. The ProCESS Investigators. A randomized trial of protocol-based care for early septic shock. N Engl J Med. 2014;370:1683-93.

28. Iwashyna TJ, Angus DC. Declining case fatality rates for severe sepsis: good data bring good news with ambiguous implications. JAMA. 2014;311(13):1295-7.

29. Levy MM, Dellinger RP, Townsend SR, Campaign SS, et al. The Surviving Sepsis Campaign: results of an international guideline-based performance improvement program targeting severe sepsis. Crit Care Med. 2010;38:367-74.

30. Suarez D, Ferrer R, Artigas A, Edusepsis Study Group et al. Cost-effectiveness of the Surviving Sepsis Campaign protocol for severe sepsis: a prospective nation-wide study in Spain. Intensive Care Med. 2011;37:444-52.

31. Routsi C, Pratikaki M, Sotiropoulou C, et al. Application of the sequential organ failure assessment (SOFA) score to bacteremic ICU patients. Infection. 2007;35(4):240-4.

32. Bouza C, Lopez-Cuadrado T, Amate-Blanco JM. Use of explicit ICD9-CM codes to identify adult severe sepsis: impacts on epidemiological estimates. Crit Care. 2016:20:313. doi:10.1186/s13054-016-1497-9.

33. Esteban A, Frutos-Vivar F, Ferguson ND, et al. Sepsis incidence and outcome: contrasting the intensive care unit with the hospital ward. Crit Care Med. 2007;35(5):1284-9.

\section{Submit your manuscript to a SpringerOpen ${ }^{\circ}$ journal and benefit from:}

- Convenient online submission

- Rigorous peer review

- Immediate publication on acceptance

- Open access: articles freely available online

- High visibility within the field

- Retaining the copyright to your article

Submit your next manuscript at springeropen.com 